7. Reprod. Fert. (1973) 35, 505-509

\title{
CHANGES IN BLOOD VASOTOCIN ACTIVITY DURING OVIPOSITION IN THE HEN
}

\author{
J. NIEZGODA, J. RZAGSA AND Z. EWY \\ Agricultural University, Institute of Applied Physiology of Animals, \\ Cracow, Poland
}

(Received 17th November 1972)

\begin{abstract}
Summary. The vasotocin level in the blood of hens during oviposition was determined on the isolated bladder of the frog, Rana esculenta. It was found that $10 \mathrm{~min}$ before oviposition, the vasotocin level in blood suddenly increased. During oviposition, it was forty-six times higher $(P<0.01)$ than that in hens with no egg in the uterus. After oviposition, the activity of vasotocin in the blood rapidly decreased.
\end{abstract}

\section{INTRODUGTION}

There is strong evidence that vasotocin (8-arginine-oxytocin) is involved in oviposition in hens. The oviduct of the hen responds to vasotocin in vivo and in vitro (Munsick, Sawyer \& van Dyke, 1960; Heller \& Pickering, 1961 ; Rzasa \& Ewy, 1968, 1970, 1971). Tanaka \& Najako (1962) reported a decrease in the content of vasotocin in the neurohypophysis of hens which was coincident with oviposition. Douglas \& Sturkie (1964), Sturkie \& Lin (1966) and Opel (1966) assayed vasotocin in the blood of laying hens and found that the concentration of the hormone increased markedly during oviposition. Sturkie \& Lin (1966) did not find a significant increase in the vasotocin level shortly before oviposition, and suggested that vasotocin does not cause oviposition but that oviposition induces its release.

The purpose of the present study was to determine the level of vasotocin in the blood of hens, within short intervals, before and after oviposition.

\section{MATERIALS AND METHODS}

Animals

Laying hens (New Hampshire), weighing about $2.5 \mathrm{~kg}$ and aged 8 months, were used. They were maintained in individual cages with free access to food and water. Records of laying were taken every $30 \mathrm{~min}$ from 07.00 to 16.00 hours. Using these data, the time of expected oviposition was calculated.

\section{Blood collection}

Two to three $1-\mathrm{ml}$ blood samples were taken from the wing vein of any one hen before, during and after oviposition. As controls, 10-ml samples were taken when the laying hens (no egg in uterus) were killed. 
Blood vasotocin assay (hydro-osmotic activity)

Blood samples were immediately centrifuged, the plasma was deproteinized with 0.1 vol. $4 \mathrm{~N}$-perchloric acid and allowed to stand for $30 \mathrm{~min}$ at $4^{\circ} \mathrm{C}$. The supernatant was separated after centrifugation, neutralized by potassium carbonate to $\mathrm{pH} 7 \cdot 4$, evaporated to dryness under vacuum, and dissolved in a test-tube containing $30 \mathrm{ml}$ Ringer solution. The composition in mmol of the Ringer solution was as follows: $\mathrm{NaCl}, 111 \cdot 0 ; \mathrm{CaCl}_{2}, 2 \cdot 7 ; \mathrm{KCl}, 3.35 ; \mathrm{NaHCO}_{3}$, 2.38; glucose, $5 \cdot 5$.

Vasotocin was assayed on preparations of isolated bladders from frogs, Rana esculenta, by a slight modification of the method of Bentley $(1958,1969)$. The movement of water across the bladder wall was proportional to the log concentration of hormone acting upon it. The frog bladders were prepared as described by Bentley (1958). The frogs were pithed and each lobe of the urinary bladder was tied to the end of a piece of glass tubing with the mucosal side facing inwards. The hemi-bladders were filled with $1.2 \mathrm{ml}$ diluted Ringer solution $(1: 5, \mathrm{v} / \mathrm{v})$. During the control period, the hemi-bladders were placed in a testtube containing $30 \mathrm{ml}$ undiluted Ringer solution and the initial permeability was measured. This solution was aerated and kept at $25^{\circ}$ C. During the experimental period, the frog bladder preparations were transferred into Ringer solution with hormone added. The water loss from the isolated bladder during a 30 -min period was measured by weighing the preparation to $1 \mathrm{mg}$ and expressed as a percentage of the original weight. Oxytocin (Syntocinon, Sandoz) was used as standard. Three standard points: $0.74,3.7$ and $7.4 \mathrm{ng}$ oxytocin $/ \mathrm{ml}$ bath solution were obtained. By plotting log dose against water loss, a linear relationship was obtained and only the bladders exhibiting a linear response were used for the assay of blood. The concentration of hormone in the blood was measured in ng of oxytocin and expressed in $\mathrm{ng}$ of vasotocin activity which is 12.2 times the oxytocic activity ( 21.9 on a unit basis) as based upon the studies of Sawyer (1960) and J. Niezgoda and J. Rzasa (unpublished observations). Direct comparison of the hydro-osmotic activity in the blood with vasotocin was not routinely performed because of the limited supply of this peptide.

\section{Enzymatic digestion}

The biological activity of vasotocin may be destroyed by incubating with trypsin.

Trypsin inactivation of plasma from hens $2 \mathrm{~min}$ after oviposition was performed by a method which was similar to that of Bentley (1969). After acidification with 1 vol. $10 \%$ acetic acid, the plasma sample was placed in a boiling water-bath for $5 \mathrm{~min}$. The sample was centrifuged and the separated supernatant was then brought to $\mathrm{pH} 7.0$ with $\mathrm{NaHCO}_{3}$ and divided into two equal portions. Trypsin (crystalline salt free, Sigma) was added to one half, to give a concentration of $30 \mu \mathrm{g} / \mathrm{ml}$. The other half served as a control. Both samples were incubated for $5 \frac{1}{2} \mathrm{hr}$ at $38^{\circ} \mathrm{G}$, at the end of which period they were again acidified, boiled, centrifuged and the supernatant brought to $\mathrm{pH} 7 \cdot 4$. The hydro-osmotic activity of both samples was compared on the frog bladder.

A statistical comparison of the results was made by the Duncan test. 


\section{RESULTS}

\section{Concentration of vasotocin in the blood of hens}

The concentrations of vasotocin in the blood at different times during egglaying are shown in Table 1 and Text-fig. 1. It was greater $4 \mathrm{hr}$ before oviposi-

Table 1. Blood vasotocin activity in the hen before, during and after oviposition

\begin{tabular}{l|c|c}
\hline \multicolumn{1}{c|}{ Treatment } & $\begin{array}{c}\text { No. of } \\
\text { birds }\end{array}$ & $\begin{array}{c}\text { Estimate of vasotocin } \\
\text { activity } \\
(\mathrm{ng} / \mathrm{ml} \text { blood })\end{array}$ \\
\hline Control (no egg in uterus) & 8 & $0.41 \pm 0.03$ \\
$4 \mathrm{hr}$ before oviposition & 7 & $0.60 \pm 0.12$ \\
10 min before oviposition & 8 & $3.01 \pm 0.18^{*}$ \\
During oviposition & 8 & $18.92 \pm 1.98^{* *}$ \\
8 min after oviposition & 8 & $2.8 \pm 0.28^{*}$ \\
\hline
\end{tabular}

Results are expressed as means \pm S.E. Significance of differences from control: $* P<0.05 ; * * P<0.01$.

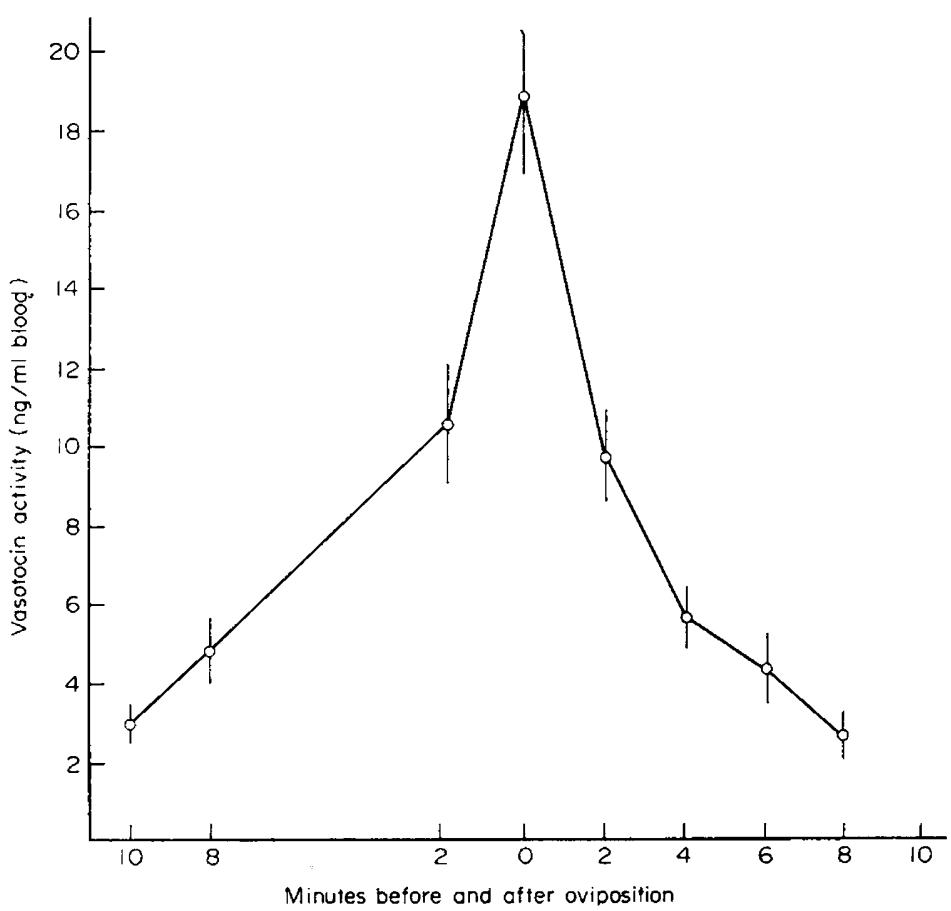

TexT-FIG. 1. Vasotocin activity in the blood of hens, before, during and after oviposition. Each point represents the average of data from seven to eight chickens. Vertical lines indicate \pm S.E.

tion than in the control hens with no eggs in the uterus. The difference, however, was statistically non-significant. Ten minutes before oviposition, the level of vasotocin was found to increase rapidly. During oviposition, it was forty-six 
times higher than that of hens with no egg in the uterus $(P<0.01)$. After oviposition, the vasotocin activity appreciably decreased. There were statistically significant differences between the results for the controls and those obtained 10, 8 and $2 \mathrm{~min}$ before oviposition and 2, 4,6 and $8 \mathrm{~min}$ after oviposition.

\section{Enzymatic degradation of plasma hydro-osmotic activity}

The proteolytic enzyme, trypsin, cleaves peptide bonds only between the carboxyl group of arginine or lysine and the adjoining amino group of another amino acid and this inactivates arginine vasotocin (Munsick et al., 1960) and arginine or lysine vasopressin (du Vigneaud, Lawler \& Popenoe, 1953).

Incubation with trypsin of an extract of blood taken from a laying hen $2 \mathrm{~min}$ after oviposition resulted in a $78 \%$ decrease in its hydro-osmotic activity (Table 2). This result suggests that the material responsible for the hydroosmotic actions of hen's blood is principally arginine vasotocin.

Table 2. The effect on the isolated frog bladder of the hydro-osmotic action of hen's blood incubated with trypsin

\begin{tabular}{l|c|c}
\hline & $\begin{array}{c}\text { Extract of } \\
1 \text { ml blood }\end{array}$ & $\begin{array}{c}\text { Extract of } \\
1 \text { ml blood }+ \text { trypsin }\end{array}$ \\
\hline $\begin{array}{l}\text { Water transfer } \\
(\mathrm{mg} / 30 \mathrm{~min})\end{array}$ & $203 \cdot 4 \pm 24 \cdot 6$ & $51 \cdot 4 \pm 10 \cdot 7$ \\
\hline
\end{tabular}

The blood samples were taken from laying hens $2 \mathrm{~min}$ after oviposition. Five samples were incubated without trypsin and five were incubated with trypsin. Values expressed as means \pm S.E.

\section{DISGUSSION}

It has been shown in the present study that during oviposition in the hen, the hydro-osmotic activity of the blood increases. The only naturally occurring substances in hens bringing about a hydro-osmotic effect are arginine vasotocin and mesotocin (8-isoleucine-oxytocin) which have been identified by chemical methods in the neurohypophysis of hens (Acher, Chauvet \& Chauvet, 1970), and cyclic $3^{\prime}, 5^{\prime}$-AMP. Degradation of hydro-osmotic activity by trypsin suggests that the hydro-osmotic activity in hens' blood is due principally to vasotocin.

Correlations between oviposition, the vasotocin content of posterior pituitaries, and that in hens' blood have been reported (Tanaka \& Nakajo, 1962; Douglas \& Sturkie, 1964; Opel, 1966; Sturkie \& Lin, 1966). Sturkie \& Lin (1966) found that the vasotocin concentration of a laying hen without an egg in the uterus was $53 \mu \mathrm{U} / \mathrm{ml}$; at 2 to $20 \mathrm{~min}$ before oviposition, it was $167 \mu \mathrm{U} / \mathrm{ml}$; and during oviposition, the concentration was 30 to 150 times higher than during the resting stage. After oviposition, the concentration dropped rapidly. In contrast to the observations of Sturkie \& Lin (1966), the level of vasotocin in this study increased significantly before oviposition. It had been found earlier in the hen that an injection of 100 to $400 \mathrm{ng}$ vasotocin $/ \mathrm{kg}$ body weight caused 
expulsion of the egg 1 to $20 \mathrm{hr}$ before the expected time of oviposition (Rzasa \& Ewy, 1970).

The same doses of vasotocin induced a significant rise in intrauterine pressure by about 19 to $67 \%$ and the increase was maintained for 22 to $71 \mathrm{~min}$, depending upon the dose (Rzasa \& Ewy, 1971).

On the basis of the data presented here, a suggestion can be made that vasotocin is involved in expulsion of the egg, although there are studies which indicate that the neurohypophysis and its hormones do not appear to be essential for oviposition (Shirley \& Nalbandov, 1956; Opel, 1965; Sturkie \& Lin, 1967).

\section{ACKNOWLEDGMENT}

The authors are indebted to Sandoz, Ltd, Basle, for a gift of synthetic oxytocin.

\section{REFERENCES}

Acher, R., Chauvet, J. \& Chauvet, M. T. (1970) Phylogeny of the neurohypophysial hormones. The avian active peptides. Eur. J. Biochem. 17, 509.

BentLey, P. J. (1958) The effects of neurohypophysial extracts on water transfer across the wall of the isolated urinary bladder of the toad Bufo marinus. F. Endocr. 17, 201.

Bentley, P. J. (1969) Neurohypophysial function in amphibia: hormone activity in the plasma. $\mathcal{J}$. Endocr. 43, 359.

Douglas, D. S. \& Sturkie, P. D. (1964) Plasma levels of antidiuretic hormone during oviposition in the hen. Fedn Proc. Fedn Am. Socs exp. Biol. 23, 150, Abstr.

du Vigneaud, V., Lawler, H. C. \& Popenoe, E. A. (1953) Enzymatic cleavage of glycinamide from vasopressin and a proposed structure for this pressor-antidiuretic hormone of the posterior pituitary. 7. Am. chem. Soc. 75, 4880 .

Heller, H. \& Pickering, B. T. (1961) Neurohypophysial hormones of non-mammalian vertebrates. 7. Physiol., Lond. 155, 98.

Munsick, R. A., Sawyer, W. B. \& van Dyke, H. B. (1960) Avian neurohypophysial hormones: pharmacological properties and tentative identification. Endocrinology, 66, 860 .

OPEL, H. (1965) Oviposition in chickens after removal of the posterior lobe of the pituitary by an improved method. Endocrinology, 76, 673.

OPEL, H. (1966) Release of oviposition-inducing factor from the median eminence pituitary stalk region in neural lobectomized hens. Anat. Rec. 154, 396.

Rzasa, J. \& Ewy, Z. (1968) Oviduct responses to neurohypophysial hormones in the hen in vitro. 6th Int. Congr. anim. Reprod. E' A.I. 1, 731.

Rzasa, J. \& Ewy, Z. (1970) Effect of vasotocin and oxytocin on oviposition in the hen. J. Reprod. Fert. 21,549 .

RzASA, J. \& EWy, Z. (1971) Effect of vasotocin and oxytocin on intrauterine pressure in the hen. $\mathcal{J}$. Reprod. Fert. 25, 115.

SAWYer, W. M. (1960) Increased water permeability of the bullfrog (Rana catesbiana) bladder in vitro in response to synthetic oxytocin and arginine vasotocin and to neurohypophysial extracts from non-mammalian vertebrates. Endocrinology, 66, 112.

ShIrLey, H. V., JR \& Nalbandov, A. V. (1956) Effects of neurohypophysectomy in domestic chickens. Endocrinalogy, 58, 477.

Sturkie, P. D. \& Lin, Y.-C. (1966) Release of vasotocin and oviposition in the hen. F. Endocr. $35,325$.

StURKIE, P. D. \& Lin, Y.-G. (1967) Further studies on oviposition and vasotocin release in the hen. Poult. Sci. 46, 1591.

Tanaka, K. \& Nakajo, S. (1962) Participation of neurohypophysial hormone in oviposition in the hen. Endocrinology, 70, 453. 